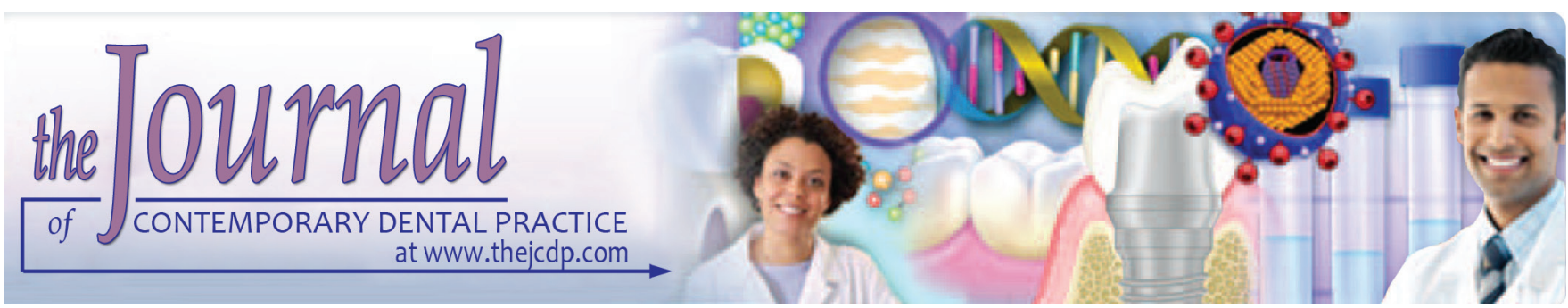

\title{
Relationship of Incisive Papilla to Maxillary Incisors and Canines
}

\author{
${ }^{1}$ Suraksha Shrestha, ${ }^{2}$ Sarita Pradhan Joshi, ${ }^{3}$ Santosh Kumar Yadav
}

\begin{abstract}
Aim: The study was carried to find a relationship between the postextraction stable landmark, the incisive papilla, and the most labial position of the maxillary central incisor teeth, which occurred in Nepalese population.
\end{abstract}

Materials and methods: Casts of the subjects selected by nonprobability random sampling meeting the inclusion criteria were obtained. Each casts were standardized with respect to the occlusal plane and a photographic technique was used to measure the distance from the tangent of the labial surface of the central incisors to the posterior border of the incisive papilla. The measurements were made using Adobe Photoshop and results were analyzed by using appropriate statistical methods. Most appropriate software (SPSS) for the purpose was used to generate all desired values.

Results: The data obtained suggested that the distance from the labial surface of maxillary central incisors to the posterior border of the incisive papilla ranged from 9 to $15.9 \mathrm{~mm}$ with a mean of $11.59 \mathrm{~mm}$ (SD 1.3). Various other results were also found after evaluation of the arch forms in relation to sex and race.

Conclusion: Within the limitations of the study, these results suggested that there is a relationship between the maxillary central incisors and the incisive papilla aiding in the anteroposterior positioning of the anterior tooth.

The clinical relevance of the study lies in application of the incisive papilla as a starting point in the preliminary location of

${ }^{1}$ Department of Prosthodontics, College of Medical Sciences Bharatpur, Chitwan, Nepal

${ }^{2}$ Department of Prosthodontics, National Academy of Medical Sciences, Bir Hospital, Kathmandu, Nepal

${ }^{3}$ Department of Oral and Maxillofacial Surgery, College of Medical Sciences, Bharatpur, Chitwan, Nepal

Corresponding Author: Suraksha Shrestha, Lecturer Department of Prosthodontics, College of Medical Sciences P.O. Box:23, Bharatpur, Chitwan, Nepal, Phone: +97756524203, e-mail: surakshashrestha@yahoo.com maxillary incisors and canines during construction of the denture in absence of preextraction records.

Keywords: Incisive papilla, Intercanine line, Maxillary incisors.

How to cite this article: Shrestha S, Joshi SP, Yadav SK. Relationship of Incisive Papilla to Maxillary Incisors and Canines. J Contemp Dent Pract 2016;17(4):306-312.

Source of support: Nil

Conflict of interest: None

\section{INTRODUCTION}

One of the problems during replacement of upper anterior teeth is about knowing the proper position of the teeth that was present when the patient had teeth. It becomes important to place teeth in proper position as this helps in achieving correct speech, esthetics, and harmonious incisal guidance. ${ }^{1-3}$

In complete denture patients, positioning of anterior artificial teeth depends on the ability to provide adequate support to the upper lip by maintaining an undistorted philtrum and nasolabial grooves and ensure proper contact of upper and lower lips at the vermillion border, which will be determined by the occlusal rim that is used as a guide. This however depends on individual assessment and may be variable. An easy method of finding the correct position will be preextraction record, but this too may not be available sometimes. The incisive papilla made of dense connective tissue covering the incisive foramen is a stable landmark, which may be used as a guide in positioning of the anterior teeth. ${ }^{4-6}$

Although the shape of the papilla shows a wide range of variation, the middle or center of the papilla is commonly used as a point of reference in many studies. ${ }^{7,8}$ One of the early studies has found a horizontal distance of 5 to $8 \mathrm{~mm}$ from the incisive papilla to the incisors. ${ }^{9}$ Martone and Mavroskoufis and Ritchie ${ }^{10-12}$ preferred 8 to $10 \mathrm{~mm}$ for this measurement, whereas Schiffman, ${ }^{7}$ related the 
canines to a line bisecting the papilla. He suggested the intercanine or canine papilla canine (CPC) line may pass through center or anterior or posterior to it depending on arch shape or irrespective of it.

Linear measurement between two objects in a three-dimensional relationship imposes problem when the objects are not aligned on the same plane in three dimensions. ${ }^{13}$ To reduce this error, the present study used a photographic technique to evaluate the points on the incisive papilla as a guide for the anteroposterior position of maxillary central incisors as used in the previous studies. ${ }^{14}$

Previous studies for the determination of relationship between incisive papilla and maxillary central incisors and canines had been done in other population groups and no such studies have been done in Nepalese population. If we can measure the distance, then it may guide us in determining the relationship so that in edentulous Nepalese population how much anterior tooth placement is appropriate during denture fabrication and is there any ethnic variation for this measurement can be known. In future, similar study may be extended to find out if there is comparative difference between the relationship in natural dentition and denture fabricated with the anterior teeth placed in a zone that is within ones subjective perception of esthetics.

\section{MATERIALS AND METHODS}

A total sample of 76 subjects categorized into four groups, each containing 19 Aryans and Mongoloids males and females were included in the study. Nonprobability sampling was done and selection was done on the criteria having full set of dentition, class I molar relation, normal overjet and overbite, symmetrical arches, and where growth was completed, that is, above 18 years of age.

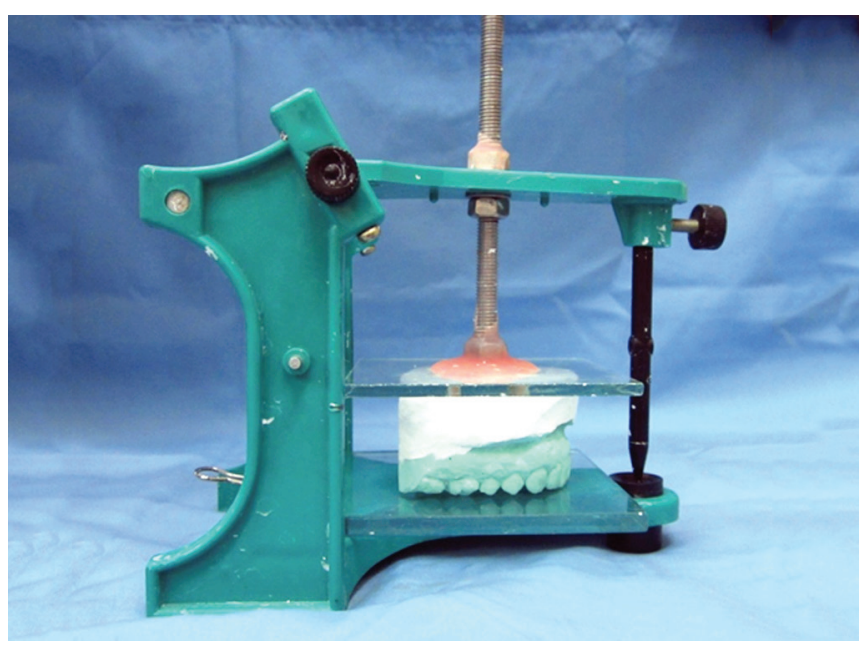

Fig. 1: Standardization of the cast
Impressions of the upper arches were made by irreversible hydrocolloid impression material (Zelgan Plus, Dentsply India Pvt. Ltd.) and the casts were poured using type III gypsum product (Kalstone Class III, Kalabhai Karson Pvt. Ltd. Mumbai, India). Standardization of the occlusal plane of each cast was done by using an articulator that was modified by fixing two glass plates on the upper and lower members of the articulator at a fixed vertical distance of $33 \mathrm{~mm}$. The casts were inverted so that the central incisors and the molars were in contact with the lower glass plate. A mix of Plaster of Paris type II gypsum product (Kaldent, Kalabhai, Dental Plaster Class II) was placed on top of the cast and the upper member with glass plate was lowered so that it contacted the plaster evenly all around until the incisal pin touched the incisal guide table and was held in that position till set to prevent setting expansion. Excess plaster around the periphery was trimmed away without touching the base. The casts thus produced were standardized with the occlusal plane parallel to the horizontal plane when the bases of the casts were placed on a flat horizontal surface (Fig. 1). Coding was done at the periphery of the casts.

The casts were placed on the platform of a photographic copying stand. White sticker with the coding was placed on the palatal aspect for easy reference and identification. A metal ruler was placed alongside the cast so that the surface of the ruler was at the same level as the occlusal plane. A camera (Nikon D80, Nikon Corporation) was used. The photographs were taken at a shutter speed of 2 seconds, the magnifying power (2/3), and a fixed distance between the camera and the casts being $25 \mathrm{~cm}$. The photographs were taken at focal length of $40 \mathrm{~mm}$, ISO speed of 250, maximum aperture of 4 , f/13 and 1/125 sec (Fig. 2).

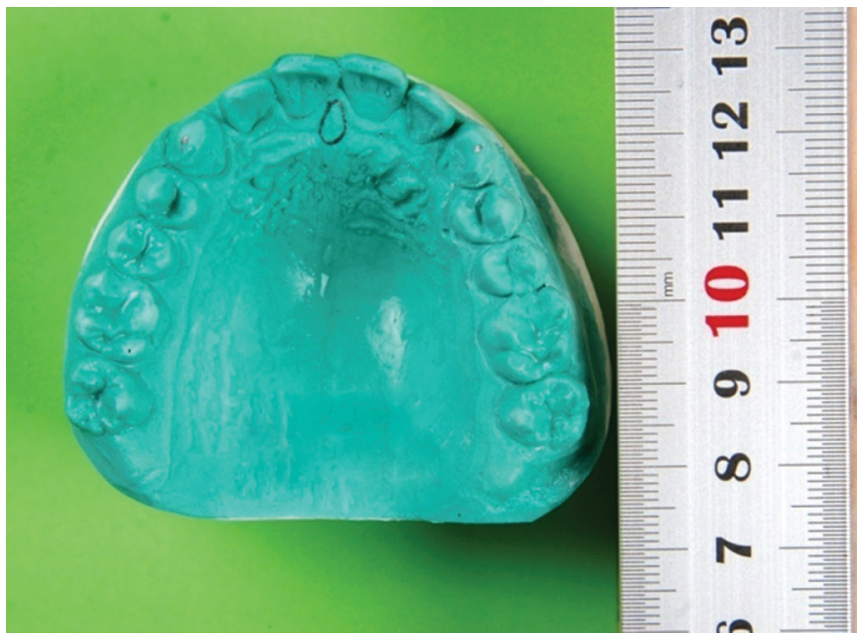

Fig. 2: Photograph of the cast. Ruler is placed along the side of the cast at the same level as the occlusal plane 
The images of the casts obtained were entered and the following information was calculated and analyzed by the computer using Adobe Photoshop 7 - the distance from the most labial contour of the central incisors (A) to the posterior point of incisive papilla (I2), that is, I2A, the region where the intercanine line or CPC line crossed the incisive papilla. For this, point $\mathrm{B}$ was marked where the CPC line intersected the midline of the papilla and distance from B to I1 was calculated. This obtained value was divided by I1I2, the total length of the papilla to get the ratio. It laid on the anterior third if the value came up to $33.3 \%$, the middle third if value came up to $66.6 \%$, and posterior third if it was more than that. Occurrence of the different arch form in relation to sex and race and their relationship to the intercanine line was also studied.

\section{RESULTS}

A total of 76 subjects participated in the study. Screening of total of 218 subjects was done and sample was selected based on the inclusion criteria and those who did not meet the criteria were excluded from the study. The mean distance between the posterior border of the incisive papilla and the labial surface of maxillary central incisors (i.e., I2-A) was $11.59 \mathrm{~mm}$ (SD 1.3) with normal distribution (Graph 1). The mean distances in male and female were $11.84 \mathrm{~mm}$ (SD 1.4) and $11.3 \mathrm{~mm}$ (SD 1.3) respectively with $\mathrm{p}$ value of 0.104 , which was not statistically significant

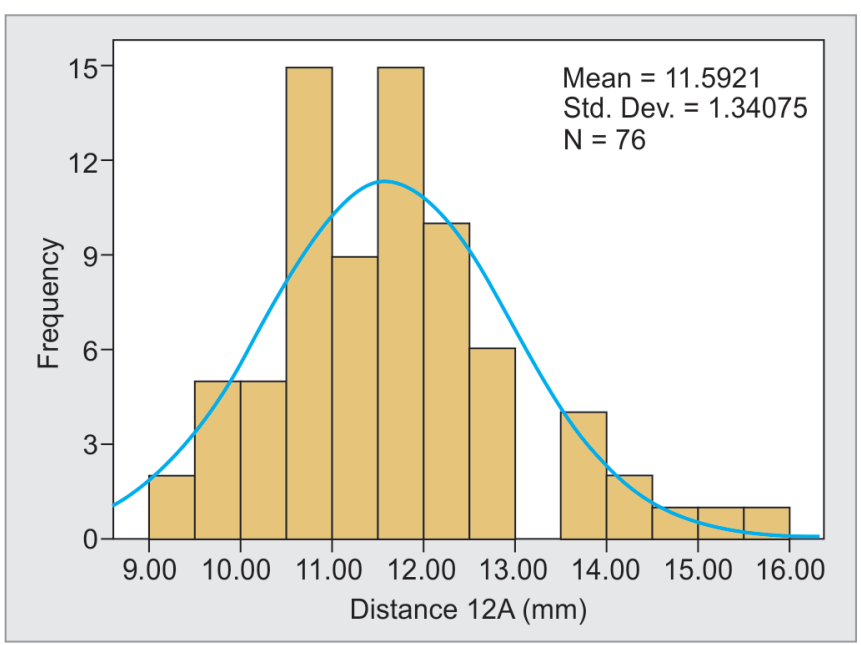

Graph 1: Normal distribution of the distance (I2-A) in the sample

Table 1: Distance between posterior border of incisive papilla (I2) and labial surface of maxillary central incisors (A) in relation to sex

\begin{tabular}{llllll}
\hline Sex & I2-A Range & Mean & $S D$ & $t$-value & $p$-value \\
\hline Male & $9.7-15.9$ & 11.84 & 1.4 & 1.64 & 0.104 \\
Female & $9.0-14.6$ & 11.3 & 1.3 & - & - \\
\hline
\end{tabular}

(Table 1). Independent t-test was used to find the relation between the distances in relation to race. The mean value in Aryans was $11.23 \mathrm{~mm}$ (SD 0.9) and Mongoloids was $12.0 \mathrm{~mm}$ (SD 1.6), which was significant at p value of 0.018 .

Oval arch was the most common type of the arch seen in both the sex and the race with occurrence of $68.4 \%$ in the total sample (Graph 2). The mean distance between the posterior border of the incisive papilla and the maxillary incisors in subjects with oval, square, and tapered arch form were $11.5 \mathrm{~mm}$ (SD 1.2), $11.9 \mathrm{~mm}$ (SD 1.7), and $11.3 \mathrm{~mm}$ (SD 0.9) respectively. One-way analysis of variance showed that the diffference was not statistically significant (Table 2). This may be due to less number of subjects with tapered arch form in the study.

Among the total sample, in $52.6 \%$ the intercanine line passed through the middle third, $32.9 \%$ passed through the posterior third and in only $14.5 \%$ it passed through the anterior third (Graph 3). In the male subjects, in $10.5 \%$ intercanine line passed through the anterior third, $60.5 \%$ passed through the middle third and $28.9 \%$ passed through the posterior third, whereas, in the female subjects, in $18.4 \%$ intercanine line passed through the anterior third, $44.7 \%$ passed through the middle third and in $36.8 \%$ passed through the posterior third. Results of the chi-square test showed that the difference in sex does not influence the relationship between intercanine line and incisive papilla (Table 3).

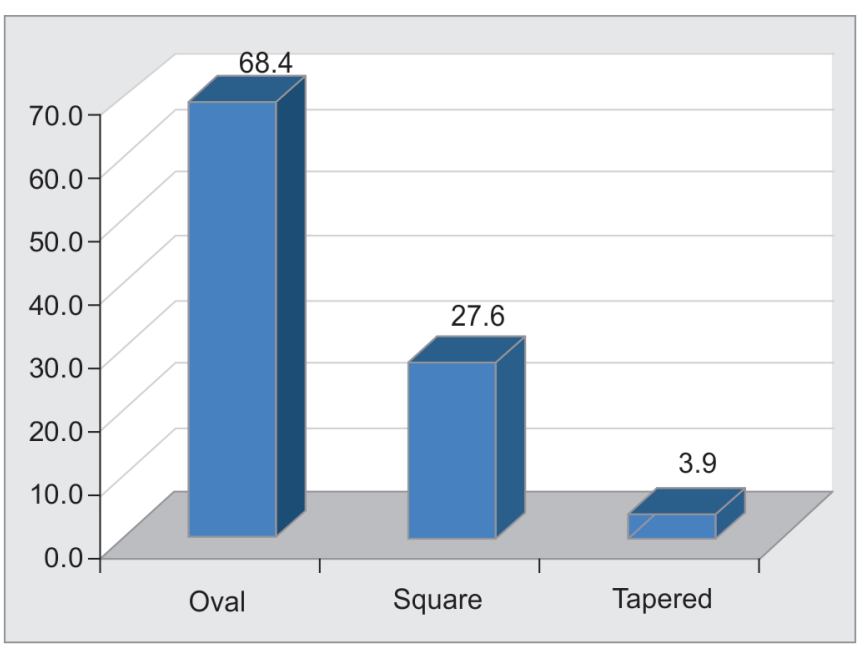

Graph 2: Distribution of dental arch form in the sample

Table 2: Distance between posterior border of incisive papilla (I2) and labial surface of maxillary central incisors $(A)$ in relation to arch form

\begin{tabular}{lllllll}
\hline \multicolumn{7}{c}{ I2-A Distance } \\
Parameter & $N$ & range & Mean & SD & $f$-value & $p$-value \\
\hline Ovoid & 52 & $9-14.6 \mathrm{~mm}$ & $11.5 \mathrm{~mm}$ & 1.2 & 0.80 & 0.454 \\
Square & 21 & $9.9-15.9 \mathrm{~mm}$ & $11.9 \mathrm{~mm}$ & 1.7 & - & - \\
Tapered & 3 & $10.3-12 \mathrm{~mm}$ & $11.3 \mathrm{~mm}$ & 0.9 & - & - \\
\hline
\end{tabular}


Relationship of Incisive Papilla to Maxillary Incisors and Canines

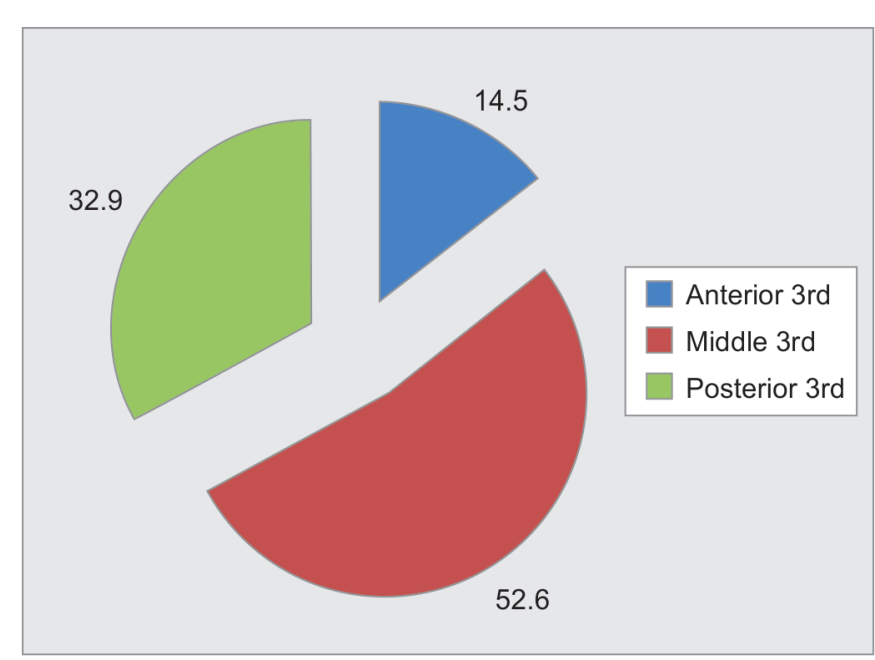

Graph 3: Location of intercanine line on the incisive papilla

Table 3: Comparison of CPC line in relation to sex (chi-square test)

\begin{tabular}{lllll}
\hline \multirow{2}{*}{ CPC line } & \multicolumn{3}{c}{ Sex } & \\
\cline { 2 - 3 } Anterior 3rd & 4 & 7 & 11 & 0.354 \\
& $10.5 \%$ & $18.4 \%$ & $14.5 \%$ & \\
Middle 3rd & 23 & 17 & 40 & \\
& $60.5 \%$ & $44.7 \%$ & $52.6 \%$ & \\
Posterior 3rd & 11 & 14 & 25 & \\
& $28.9 \%$ & $36.8 \%$ & $32.9 \%$ & \\
& 38 & 38 & 76 & \\
\hline Total & $100 \%$ & $100 \%$ & $100 \%$ & \\
\hline
\end{tabular}

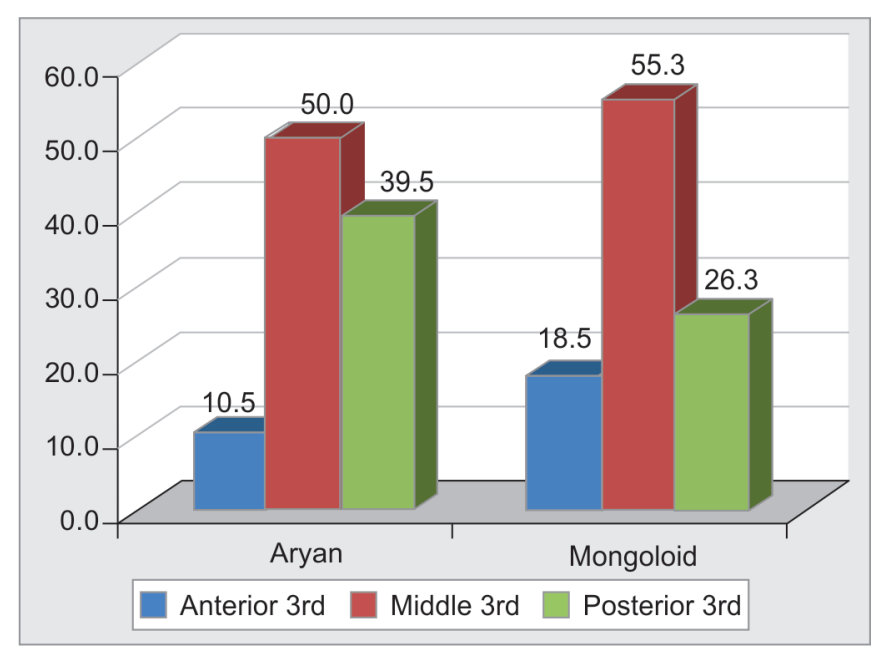

Graph 4: Distribution of CPC line in Aryans and Mongoloids

The intercanine line or CPC line passed through the anterior border in $10.5 \%$ of Aryans, $18.4 \%$ of Mongoloids, through the middle third in 50\% of Aryans and 55.3\% of Mongoloids and through the posterior border in 39.5\% of Aryans and $26.3 \%$ of Mongoloids. The result showed that in both the Aryans and Mongoloids, maximum had the line passing through the middle third of the papilla. The result was analyzed statistically and was found to be not significant (Graph 4). The intercanine lines of 55.8\%
Table 4: Comparison of location of CPC line in relation to dental arch form

\begin{tabular}{|c|c|c|c|c|}
\hline \multirow[b]{2}{*}{ Location } & \multicolumn{3}{|c|}{ Shape } & \multirow[b]{2}{*}{$p$-value } \\
\hline & Oval & Square & Tapered & \\
\hline \multirow[t]{2}{*}{ Anterior 3rd } & 4 & 7 & 0 & 0.072 \\
\hline & $7.7 \%$ & $33.3 \%$ & $0.0 \%$ & \\
\hline \multirow[t]{2}{*}{ Middle 3rd } & 29 & 9 & 2 & \\
\hline & $55.8 \%$ & $42.9 \%$ & $66.7 \%$ & \\
\hline \multirow[t]{2}{*}{ Posterior 3rd } & 19 & 5 & 1 & \\
\hline & $36.5 \%$ & $23.8 \%$ & $33.3 \%$ & \\
\hline Total & 52 & 21 & 3 & \\
\hline
\end{tabular}

of subjects with oval arch form and $66.7 \%$ with tapered arch form passed through the middle third of the papilla, whereas only $42.9 \%$ with square form passed through the middle third. Because of the small number of sample in tapered form, it is difficult to assess whether the differences were statictically significant (Table 4).

\section{DISCUSSION}

The position of maxillary incisors may affect the esthetic and function during denture fabrication and a stable landmark such as incisive papilla would be an important anthropometric tool facilitating prosthetic teeth arrangement as it guides for setting of artificial teeth. ${ }^{1,4,11,15}$

Thus, in the present study, relation between the incisive papilla and maxillary anteriors has been studied. Even though an objective measurement cannot be relied upon all the time, it becomes important as a starting point in the placement of anterior teeth. Dental casts have been used by many authors to measure the tooth dimension and distances of the landmarks in many studies and many of them have used alginate as an impression material. ${ }^{7-14,16-31}$ The standardization of cast was necessary as linear measurement between two points or objects in a space would be difficult when the objects are not arranged on the same plane. In the past, studies have been done by using various methods like vernier caliper with two limbs that are adjustable with shorter and longer limbs contacting the objects at two different planes to measure the linear distance, ${ }^{16}$ some used the contourmeter to orient the plane ${ }^{21}$ with measuring dial guage, while Grave and Beker used Ney surveyor and vernier caliper for the same. Sawaris used pin, rod, and plate method for the measurement and some used modified dividers ${ }^{12}$ and some have used profile projection method. ${ }^{13}$

In the present study, we used the photographs method to measure the linear horizontal distance between the maxillary incisors and the incisive papilla. Similar methods have been used by Lau and Clark, Khalaf. ${ }^{14,30}$ 
The orientation of the casts to a flat occlusal plane is necessary during the photography to reduce the parallex error. $^{31}$ This was achieved by standardizing each casts to a flat plane. This study used two glass slabs separated at a distance and fixed to the arms of upper and lower members of the articulator to produce the casts. The water leveling scale was used to check the plane. The orientation of the casts was standardized by defining the occlusal plane, which is formed by the most incisal points of the central incisors and the most occlusal points of the left and right first molars (which are usually the tips of the palatal cusps). This orientation was chosen because this plane was more comparable to complete denture situation as with balanced occlusion, the palatal cusps of the maxillary first molar are always on the occlusal plane of the denture during teeth setting. ${ }^{32,33}$ All the measurements were the straight linear distances in millimeter, which are parallel to the reference plane, that is, the measurements of the orthographic projections of the relationship between the maxillary central incisors and the incisive papilla in relation to the reference plane was calculated in all the cases. The axial angulation and rotation of the teeth were ignored in all the cases.

The papilla has been used as a landmark in this study. Longer the edentulism, more anteriorly the papilla was situated because of the flatness. The most posterior point of the incisive papilla was used as an anatomic mark in all the horizontal measurements because it could be easily and exactly located and it is less liable to be affected by the soft tissue mutilation unlike the anterior point. The posterior point was also used by other authors. $8,13,14,16,21$ However, measurements have also been done from the middle point of the papilla $a^{6,7,9-12,14,20,30}$ and some had done from both points. ${ }^{14,26}$

In the present study, the mean distance between the labial surface of the maxillary incisors and the posterior border of the papilla was found to be $11.59 \mathrm{~mm}$ (SD 1.3). Ortman and Tsao ${ }^{13}$ has found this distance as $12.45 \mathrm{~mm}$ with standard deviation of 3.867. Study done by Ehrlich and Gazit found this distance to be $12.31 \mathrm{~mm}$ whereas, in Southern Chinese population Lau and Clark found this value to be ranged from 9.17 to $16.58 \mathrm{~mm}$ with a mean of $12.71 \mathrm{~mm}$ (SD 1.49). In Jordanians, the distance ranged from 8.29 to $17.49 \mathrm{~mm}$ with a mean of $12.93 \mathrm{~mm}$ (SD 1.66) as measured by Amin WM 40 and in south Indian population it was found to be $11.92 \mathrm{~mm}$ (SD 2.01) as measured by Solomon and Arunachalam. ${ }^{25}$

When comparing the result with Caucasians, a difference of about $1.6 \mathrm{~mm}$ is seen in this population. This may be due to prominent premaxilla compared to the Western populations. The sex had no influence on the distance between the incisive papilla and the maxillary incisors as in many other studies. This did not influence placing the incisors forward or backward in males and females. The mean distance ranged from $11.84 \mathrm{~mm}$ (SD 1.4) in males and $11.3 \mathrm{~mm}$ (SD 1.3) in females with no significant difference ( $p$ 0.104) and the average value $11.59 \mathrm{~mm}$ could be used in both the sex.

Comparing the two ethnic groups in Nepal, the mean distance in Aryans is $11.23 \mathrm{~mm}$ with standard deviation of 0.9 and in Mongoloids is $12.0 \mathrm{~mm}$ with standard deviation of 1.6 , which is compatible to the findings of Ortman and Tsao $12.4 \mathrm{~mm}$, also Grave and Beker proved this similar measurement as 12 to $13 \mathrm{~mm}$. The difference between the distances was significant at $p$ value of 0.018 and p 0.104, and suggests slight forward positioning in the Mongoloids than in Aryans. This may be due to protrusion of jaws seen in the Mongoloids and prominent and increased length of the papilla found in this group. ${ }^{13,16}$ In contrast, the study done by Isa and Abduladhi, in Malay, Indian, and Chinese dentate and edentulous subjects, the mean distance from the midpoint was found to be $9.591 .0 \mathrm{~mm}$. There was no significant difference in relation to ethnic groups $(p>0.05) .{ }^{29}$

The common arch form in the present study was oval (68.4\%), followed by square (27.6\%) and tapered (3.9\%). Similar result was found by Ehrlich and Gazit, who found oval $(64.4 \%)$, square $(27.6 \%)$, and tapered $(10 \%)$. The common arch form had no relation in terms of sex and race, whereas comparing square arch form in Aryans and Mongoloids; it was more common in Mongoloids with ratio of 3.2:1, whereas tapered arch was not seen in any Mongoloids. In Korean population, the common arch form was square, which was commonly found in Mongoloid origin, and in North Americans, tapered arch was most common. ${ }^{34}$ Arch form was determined by morphological description and no such calculations were done as studies by other authors also used the same descriptive classification. When classification was confusing, judgment was done by asking for classification multiple times by the same and by other observers. ${ }^{8,21}$ The incisive papilla and incisor distance measured has no relation in terms of arch form, as ovoid had $11.5 \mathrm{~mm}$ (SD 1.2), square $11.9 \mathrm{~mm}$ (SD 1.7), and tapered had $11.3 \mathrm{~mm}$ (SD 0.9) with p value 0.454 . However, inconsistency of the result may be due to smaller number of subjects in tapered arch group. Similarly, result of Zia et $\mathrm{al}^{35}$ showed ovoid arch being common in either sex and no significant difference between males and females in threefourth of dentate subjects regarding the type of dental arch and incisor papilla distance.

To establish some relation between the incisive papilla and the canines, a line was drawn passing from the left canine to right canine. In all the samples, it passed through the incisive papilla and this intercanine line was called canine papilla canine line or CPC line. The CPC line 
passed through the middle third in $52.6 \%$ of the subjects, which was closely matched with the study of Lau and Clark where $57.3 \%$ subjects had the line passing through the middle third. The CPC line passed through the middle third in 50\% Aryans and 55.3\% Mongoloids, and $60.5 \%$ males and $44.7 \%$ females, followed by posterior and anterior third. There was no racial and gender variation in the location. Dental arch form also did not have significant effect on the location of the CPC line as in most of the cases. It passed through the middle third. Similar results were found by other authors. $7,12,14,19,26,30,36$

The intercanine line was used in this study rather than the line passing through the distal-most points of the canines as the most distal point of the canine was not easier to find than the tips of the canines. Ehrlich and Gazit ${ }^{8}$ found that in $57.6 \%$ intercanine lines passed through the center of the papilla. Sawiris ${ }^{36}$ showed in $64 \%$ of subjects the intercanine line was situated $1 \mathrm{~mm}$ from the center of the papilla. Mavroskoufis and Ritchie ${ }^{12}$ found the middle of the incisive papilla in Caucasians appeared to lie close to the intercanine line. The discrepancy between the intercanine line and the middle of the papilla in $93.4 \%$ of the subjects was less than $2 \mathrm{~mm}$. Grove and Christensen $^{21}$ stated that in $92 \%$ of the 50 subjects the posterior point of the incisive papilla was approximately $3 \mathrm{~mm}$ anterior to a line between the distal points of the canines.

One of the findings of the study by Solomon was the location of the incisive papilla to the intercanine line. In $93 \%$ of the subjects, the tip of the canines and incisive papilla were the same line, whereas, in the present study, it was all within the papilla border. The intercanine line passed through the middle of the papilla in $78 \%$, along the base in $14.1 \%$ and in $0.4 \%$ at its anterior border. It was anterior in $6.5 \%$ and posterior in $0.5 \%$ within $1.5 \mathrm{~mm}$ distance to the intercanine line. ${ }^{25}$ In the present study, all the intercanine lines fell within the boundary. When the ratio of the distance between the intercanine line and the anterior border was 33\% of the total length of the papilla, it fell on the anterior third. If it was between 34 and $66 \%$, it fell on the middle third and if the ratio was greater than $66 \%$, it fell on the posterior third.

\section{CONCLUSION}

The relationship of the incisive papilla to the maxillary permanent central incisors and canine teeth was determined in 76 dentulous subjects between the ages 18 and 30 years with equal distribution of sex and race (Aryans and Mongoloids). The landmarks were recorded by photographic method with real images of 1:1 ratio. All the measurements were done using computer software after the images were transferred to the computer. The measurements were correlated with sex and race using independent sample $t$ test. The distance was significant in relation to the race, whereas it was not significant in relation to sex. The most common form of arch was found to be oval shaped and the least common was tapered irrespective of sex and race in the sample. The relation of the intercanine line was such that it lay within the boundary of the incisive papilla and most of them passed through the middle third of the papilla (52.6\%). Chi-square test showed the relation between the location of the intercanine line in relation to sex, race, and dental arch form. In all the cases, maximum sample were in the middle third.

The incisive papilla is a useful anatomical landmark to locate the position of central incisors and canines in upper complete dentures. However, clinicians must base their judgments on the basis of combination of biometric guides and application of phonetic tests to achieve the most functionally and esthetically effective scheme for placement of artificial teeth.

\section{REFERENCES}

1. Zarb, GA.; Bolender, CL.; Eckert, SE.; Fenton, AH.; Jacob, RF.; Mericske-Stern, R. Prosthodontic treatment for edentulous patients. 12th ed. Mosby: Elsevier Health Sciences, 2003. p. 309-311.

2. Winkler, S. Essentials of complete denture. 2nd ed. Missouri, U.S.A: Brentwood, 1994. p. 205-209

3. Heartwell. Syllabus of complete denture. 4th ed. Philadelphia, Pennsylvania: Lea \& Febiger; 1986. p. 418.

4. Boucher Co. The current state of prosthodontics. J Prosthet Dent 1960;10:411-425.

5. Watt, DM.; Macgregor, AR. Designing partial dentures. London: Saunders; 1984. p. 184-199.

6. Watt DM. Tooth positions on complete dentures. J Dent 1978 Jun;6(2):147-160.

7. Schiffman P. Relation of the maxillary canines to the incisive papilla. J Prosthet Dent 1964;14:469-472.

8. Ehrlich J, Gazit E. Relationship of the maxillary central incisors and canines to the incisive papilla. J Oral Rehabil 1975 Jul;2(3):399-312.

9. Harper RN. The incisive papilla, basis of technic to reproduce the positions of key teeth in prosthodontia. J Dent Res 1948;27(6):661-668.

10. Martone AL. Clinical application of concepts of functional anatomy and speech science to complete denture prosthodontics. J Prosthet Dent 1963;13:204-228.

11. Alexder L. Martone. Effects of complete dentures on facial esthetics. J Prosthet Dent 1964;14(2):231-255.

12. Mavroskoufis F, Ritchie GM. Nasal width and incisive papilla as guides for the selection and arrangement of maxillary anterior teeth. J Prosthet Dent 1981 Jun;45:592-597.

13. Ortman HR, Tsao DH. Relationship of the incisive papilla to the maxillary central incisors. J Prosthet Dent 1979;42(5): 492-496.

14. Lau GCK, Clark RFK. The relationship of the incisive papilla to the maxillary central incisors and canine teeth in Southern Chinese. J Prosthet Dent 1993 Jul;70(1):86-93. 
15. Sellen PN, Jagger DC, Harrison A. Computer-generated study of the correlation between tooth, face, arch forms, and palatal contour. J Prosthet Dent 1998 Aug;80(2):163-168.

16. Grave AM, Becker PJ. Evaluation of the incisive papilla as a guide to anterior tooth position. J Prosthet Dent 1987 Jun;57(6):712-714.

17. Huang S-J, Chou T-M, Lee H-E, Wu Y-C, Yang Y-H, Ho C-D, Huang PS. Exploring the distance between upper central incisor edge and incisive papilla in Taiwanese population. Taiwan J Oral Med Health Sci 2004;20:4-10.

18. Fu PS, Hung CC, Hong JM, Wang JC. Three-dimensional analysis of the occlusal plane related to the hamular-incisivepapilla occlusal plane in young adults. J Oral Rehabil 2007 Feb;34(2):136-140.

19. Watt DM, Likeman PR. Morphological changes in the denture bearing area following the extraction of maxillary teeth. Br Dent J 1974 Mar 19;136(6):225-235.

20. Hickey JC, Boucher CO, Woelfel JB. Responsibility of the dentist in complete dentures. J Prosthet Dent 1962;12: 637-653.

21. Grove HF, Christensen LV. Relationship of the maxillary canines to the incisive papilla. J Prosthet Dent 1989 Jan;61(1):51-53.

22. Mc Arthur DR. Determining approximate size of maxillary anterior artificial teeth when mandibular anterior teeth are present. Part I Size relationship. J Prosthet Dent 1985 Feb;53(2): 216-218.

23. Abdullah MA. Inner canthal distance and geometric progression as a predictor of maxillary central incisor width. J Prosthet Dent 2002 Jul;88(1):16-20.

24. Jayachandran S, Ramachandran CR, Varghese R. Occlusal plane orientation: a statistical and clinical analysis in different clinical situations. J Prosthodont 2008 Oct;17(7):572-575.

25. Solomon EG, Arunachalam KS. The incisive papilla: a significant landmark in prosthodontics. J Indian Prosthodont Soc 2012 Dec;12(4):236-247.

26. Amin WM, Taha ST, AJ-Tarawneh SK, Saleh MW, Ghzawi A. The relationship of the maxillary central incisors and canines to incisive papilla in Jordanians. J Contemp Dent Pract 2008 Jul 1;9(5):42-51.

27. Park YS, Lee SP, Paik KS. The three-dimensional relationship on a virtual model between the maxillary anterior teeth and incisive papilla. J Prosthet Dent 2007 Oct;98(4):312-318.

28. Guldag MU, Sentut F, Buyukkaplan US. Investigation of vertical distance between incisive papilla and incisal edge of maxillary central incisors. Eur J Dent 2008 Jul; 2(3):161-166.

29. Isa ZM, Abdulhadi LM. Relationship of maxillary incisors in complete dentures to the incisive papilla. J Oral Sci 2012;54(2): 159-163.

30. Khalaf HA. Evaluation of the incisive papilla as a guide to the maxillary central incisors and canine teeth position in Iraqi and Yemenian samples. J Fac Med Baghdad 2009;51(2):146-150.

31. Liu J, Yang A, Fang Z, Tan Y, Sun J. Experimental research of the positional relationship between the incisive papilla and maxillary anterior teeth based on three dimensional vision measurement. Shanghai Kou Qiang Yi Xue 2013 Apr;22(2): 202-205.

32. Tarazi E, Ticotsky-Zadok N. [Occlusal schemes of complete dentures - a review of the literature]. Refuat Hapeh Vehashinayin (1993) 2007 Jan; 24(1):56-64, 85-86.

33. Singh K, Lakshmi N, Agnihotri Y, Suvarna SR, Sahoo S, Kumar P. Three-dimensional analysis to compare parallelism of occlusal planes to the hamular notch-incisive papilla plane in dentulous and edentulous subjects. Eur J General Dent 2013:2(3):286-291.

34. Kook YA, Nojima K, Moon HB, McLaughlin RP, Sinclair PM. Comparison of arch form between Korean and North American white populations. Am J Orthod Dentofacial Orthop 2004 Dec;126:680-686.

35. Zia M, Azad AA, Ahmed S. Comparison of distance between maxillary central incisors and incisive papilla in dentate individuals with different arch froms. J Ayub Med Coll Abbottabad 2009 Oct-Dec;21(4):125-128.

36. Sawiris MM. The role of anthopoemetric measurement in design of complete denture. J Dent 1977;5(2):141-148. 